\title{
PROBLEMS OF EVACUATION
}

\begin{abstract}
A SPECTS of evacuation problems are discussed in recent articles in the Political Quarterly and the Quarterly Review, which malke a number of useful suggestions for their solution. Reviewing the working and present position of the evacuation scheme in the Political Quarterly, Mr. A. D. K. Owen suggests that in Scotland uncertainty concerning the financial aspects of evacuation played a considerable part in deterring many people from going away or permitting their children to leave vulnerable areas. He considers that more effective publicity, directed to the poorer sections of the population, relating to the financial implications of evacuation might have resulted in a more satisfactory response.

While in the reception areas the situation is in many ways not unsatisfactory, it is difficult to see how the evacuation scheme can be successfully rebuilt in the absence of compulsory powers. Mr. Owen suggests that certain districts within the existing evacuation areas should be scheduled as specially dangerous-all places, for example, within a certain distance of military or naval targets, shipbuilding yards, docks or important railway junctions-and children of sehool age prohibited from living in them save in very exceptional circumstances. He also suggests that the law of school attendance should be amended so as to prevent parents from bringing their children home from reception areas without good reasons.
\end{abstract}

The first measure would involve transferring all schools serving the prohibited districts to reception areas, and the second would make it possible to plan ahead with some assurance that the population for which plans are being made would not melt away before they matured. Schools in those parts of the evacuation areas which lie outside the prohibited districts should be opened as soon as they have been given reasonable protection, but a fresh approach made to parents in these areas to persuade them to allow their children to be evacuated or re-evacuated.

Capt. Frederic Evans, in the Quarterly Review, directs attention rather to measures which might be taken in the reception areas to organize new life for evacuees within the strange environment to which they have been taken. He emphasizes the importance of balancing out school accommodation and staffs, the development of specialized accommodation for difficult children, clinics, recreation and other purposes. Holiday camps, youth hostels, and village halls could all offer important contributions, and if well organized might contribute to a closer wedding of the town to the country, with far-reaching and beneficial consequences to the whole nation.

Psychological and financial problems have to be faced and the careful planning of the medical services in the country is of special importance. Their staffing and provision pre-suppose a national service. Capt. Evans urges that the considerable expenditure involved in the various social services required to solve these problems must be incurred or we may find the War has been fought in vain.

Dr. W. A. Robson's article, "Evacuation, Town Planning and the War", is concerned with the wide issues which are opened up by the evacuation not merely of school children, but also of civil servants, business houses, ete., and the imperative need for some central control and planning if chaos is not to result from the indiscriminate location not merely of industry in the reception areas but also from the tremendous demand for premises and land by the civil and military authorities. The demands of the War Office and the Air Ministry for camps and aerodromes must be met without question or delay ; but it would be the gravest mistake to permit all these new and necessary constructions arising from these as well as from civil needs, and also the consequences of evacuation, to take place in utter confusion or on the basis of laissez-faire, and with a complete disregard of the peace-time situation which will follow the War.

For this reason, and because our war-time exigencies are strangely consistent with socially desirable peace-time purposes, Dr. Robson views with such alarm the abandonment by the Government of the reports of the Royal Commission on the geographical distribution of the industrial population. Town and country planning should now acquire a new and more important status and be placed in the hands of a strong central department competent not only to deal with the special needs of the Service departments and the Government offices, but also to take over the long overdue task of directing the location of industry and formulating a national plan for the whole country.

\section{AIR CONDITIONING}

$\mathrm{A}^{\mathrm{N}}$ $\mathrm{N}$ abstract of a paper on "Air Conditioning" read by W. Chambers to the North Midland Section of the Students of the Institution of Electrical Engineers and published in the Institution's Journal of December gives a clear account of the objects to be attained by air-conditioning and of the methods by which it can be done.

The object is to maintain in a building an atmosphere that is most beneficial to the health of the occupants or which is most suitable to the process of manufacture carried on therein. To maintain these conditions, it is necessary to control the heat content or temperature, the purity, the moisture content (humidity) and the distribution of the air. A ventilating scheme in which the air is filtered, comfortable in temperature and adequate in volume, is sometimes considered entirely satisfactory, and little if any attention is paid to its moisture content, although the latter has a great effect upon the comfort of the human body. 
In the case of public buildings where the number of occupants may be large and the lighting load large in comparison with the human content, the heat and emanations produced by the occupants have to be counteracted. The atmosphere should have a normal natural temperature and moisture content, with sufficient movement of the air to overcome stagnation.

To raise the temperature of the air in winter, it is only necessary to pass it over a hot surface, and most air heaters therefore consist of finned tubes which are steam-heated, and over which the air is forced to pass by means of centrifugal type fans. It must be remembered that heating lowers the relative humidity, owing to the fact that heated air is contained in a larger volume, but it still carries the same initial quantity of moisture as before heating took place. A pre-heated spray washer to maintain the humidity under control is often used.

In summer, in cooling the air the reverse applies, the relative humidity being increased, so that drying is necessary. This is done by exposing the air to cold surfaces or cold spray, whereby excess moisture is condensed and the air left saturated at a lower temperature. This can be done by mixing the air with air which has not been cooled.

In industrial neighbourhoods, it is necessary to extract from the air dust and grime particles. For this purpose filters are used, and the entire volume of air to be circulated is passed through them. Washers, viscous-type filters and throw-away type filters are used. The last type consists of a cheap fabric which may be cleaned by a vacuum cleaner nozzle, but it is more usual to dispense with them entirely and replace by new fabric. The efficiency of these filters is claimed to be greater than 99 per cent with removal of particles down to $1 / 30,000$ in.

The comfort chart which the American Society of Heating and Ventilating Engineers has evolved shows that summer and winter conditions vary and that the average conditions are a temperature of $72^{\circ} \mathrm{F}$. with a relative humidity of 50-60 per cent for summer and a temperature of $66^{\circ}$ for winter with a similar humidity.

In an actual installation, the air is first passed through a filter and then tempered in a preheater; this has the effect of preventing the incoming air from being too cold and freezing the water in the washer. The science of air-conditioning is making great progress. The engineer of the future who aims at a thorough mastery of his subject must know physics, especially thermodynamics, and have also some knowledge of those branches of chemistry, medicine, biology, psychology and physiology connected with it.

\section{ORIGIN OF THE CORPUS CALLOSUM}

$\mathrm{I}^{\mathrm{N}}$ "Man's Place in Nature", T. H. Huxley expressed some astonishment at the abrupt appearance of a corpus callosum in placental mammals, suggesting that this phenomenon represents "the greatest leap anywhere made by Nature in her brainwork". Later on, between 1887 and 1895, this problem was studied by a number of anatomists, including Osborn, Zuckerkandl, Symington, Herrick and Elliot Smith, and several divergent opinions were expressed as to the phylogenetic origin of the commissure.

The evidence was clarified to a very considerable extent by the detailed work of Elliot Smith, who made full use of his opportunities in Australia for studying the comparative anatomy of monotreme and marsupial brains. Elliot Smith believed the corpus callosum to be a neomorph which is characteristic of eutherian mammals, and he suggested that its development was facilitated by the bilaminar formation of the fornix commissure which is developed in the marsupial brain. This observation also led him to infer the probability of a metatherian ancestry for placental mammals. Elliot Smith further directed attention to the distorting effect of the corpus callosum on the hippocampal formation, whereby the latter becomes stretched out into a thin atrophic layer of grey matter-the indusium. The latter, again, becomes continuous anteriorly with the hippocampal rudiment found in the precommissural area of the cerebral hemisphere. All these observations, and the conclusions whch are to be drawn from them, have been accepted for many years by most comparative neurologists.

Quite recently, however, the whole question has been raised afresh by the eontention of an Australian anatomist-Dr. A. A. Abbie ${ }^{1}$ - that in its develop- ment the corpus callosum does not, after all, make use of a previous pathway already established by the fibres of the dorsal lamina of the fornix commissure, but is an entirely new commissural connexion formed along a zone of fusion between the two cerebral hemispheres which occurs dorsal to the hippocampus. According to Abbie's interpretation, the indusium is thus not the rudiment of the hippocampus at all, but a representative of an adjacent cortical area, the subiculum.

In a communication to NATURE ${ }^{2}$ Abbie discussed the bearing of his conception of the origin of the corpus callosum on the ancestry of the Eutheria. It is interesting to note, however, that his conclusions do not differ essentially from those inferred by Elliot Smith on other grounds, for Abbie contends that the expansion of the neocortex and the consequent formation of a hippocampal fissure are the minimal requirements for the development of a corpus callosum, and this condition is first realized in the brain of monotremes and marsupials.

But it is important to note that Abbie's interpretation of the development of the corpus callosum has not passed unchallenged. In the current issue of the Journal of Anatomy another anatomist in Australia, Prof. F. Golby, has subjected the new thesis to a very critical examination ${ }^{3}$. His observations suggest that Abbie has been misled in his interpretation of microscopic sections by the distortion of the hippocampal formation at the subsplenial flexure, a distortion which has resulted in a reversal and displacement to a dorsal position of some of the fibres of the fornix commissure (forming the fornix superior), as well as in an illusory appearance in the position of the corpus callosum relative 